\title{
Popular Science Between News and Education: A European Perspective
}

\author{
Arne Schirrmacher
}

Published online: 1 March 2011

(C) Springer Science+Business Media B.V. 2011

Typically, scholars that do research on models and structures of science education understand their work as rather independent of issues like popularization and journalism. Further academic pursuits that ask about the history of popular science including its specific audiences and genres on the one hand and that try to explore the preferable ways for journalists to write about news from science and technology on the other hand may exist in their own right. Systematic science education, one may hold, in particular as it is related to institutions such as schools and universities must be confounded neither with popular readings that blend entertainment with telling stories about science nor with science news within the daily press. While the latter would be too unsystematic to count as education, the former may not really teach new skills but rather amount to second-order discussion on scientific developments. Education, popularization, and journalism may hence appear as distinguishable endeavors that all relate to science but do not necessary function in connection.

The collection of five papers in this special issue intends to disproof this view-at least to some extent. The argument becomes particularly strong from a wider European perspective, and rather than concentrating on the "big" science nations like Britain, Germany and France one may consider the developments in the European periphery, where educational institutions (even in the twentieth century) still had to develop a wide availability and an independent standing (Daum 2009; Papanelopoulou et al. 2009). Within the process of creating a general scientific literacy the Greek, Portuguese, and Spanish cases show to what extent popularization and science news in the daily press have contributed to a complex educational project. Along the same lines it is often hard to distinguish popular books on science from early science textbooks, a distinction that is just so obvious for academic professionalism in the "big" science nations. For this reason it appears reasonable not to divide the various discourses on science too quickly into education, popularization, and science news and better to concentrate on the circulation of knowledgeor on "knowledge in transit" (Secord 2004) - in which all three fields may participate and interact. This view opens up a particular diverse field. Events like earth quakes or solar

A. Schirrmacher $(\bowtie)$

Max Planck Institute for the History of Science, Boltzmannstr. 22, 14195 Berlin, Germany

e-mail: aschirrmacher@mpiwg-berlin.mpg.de 
eclipses draw attention from all sides and may also help institutionalize structures in the respective scientific fields. Old as well as newly established organizations like those of the Spanish Jesuits having a strong tradition in education, the transformation of the Hungarian educational system and its international relations, or even the early German radio trying to invent new models to meet a high aim of culture that included scientific knowledge combined and bridged education, popularization, and journalism in different ways. All these developments, however, always related to national contexts of society, culture, and politics.

In the first case study on Greece Mergoupi-Savaidou, Papanelopoulou, and Tzokas investigate the creation of a general scientific literacy within a country that never excelled in modern scientific of technological fields. Here the daily press played a central role in the circulation of scientific knowledge and produced surprisingly rich accounts of science and technology at the beginning of the twentieth century. The authors pay particular attention both to historiographical questions related to studying newspapers as historical sources, viz. questions of transmission, reception, and appropriation, and the particular social, cultural, and political context in which Greece was constructing its own national identity between West and East, a process in which rhetoric on science and technology was strongly employed.

By shifting the focus on natural events that had special impact on the development of Portuguese institutions of scientific research-in particular earthquakes, volcanoes, and weather events-, newspapers as means of circulating scientific knowledge are investigated by Simões, Carneiro, and Diogo both for metropolitan and rural audiences in Lisbon and on the Azores, resp. In different ways they contributed to and reflected on the integration of Portugal into international scientific networks, seismologic stations, observatories, and other scientific institutions. Science popularization provided not only some basic scientific literacy to larger audiences but it also played a strong role in integrating and consolidating Portuguese science within its society after the turn to the twentieth century.

Observatories were also important for science dissemination in pre-Civil War Spain. Jesuits dominated for centuries the Spanish educational system and also the most important popular science journal after 1914 Ibérica was published by members of the Society of Jesus based at the Ebro observatory. Herran explores the impact or rather the tension between Catholicism and modernism for the years between 1914 and 1936 by focusing on the discourse on radioactivity in the journal. In this way Ibérica can be used to exhibit the ways in which religious or other ideological frames shaped science education and science communication.

The last two papers of this special issue deal with Hungary and Germany and take two views on particular structures of education, in a more traditional institutional way for Hungary and in a more unconventional media related way for Germany. Using a rather long-term perspective, Frank in his contribution on Hungary explores the creative and innovative scene of fin-de-siècle Budapest and Hungarian science education, starting with physicist and science organizer Loránd Eötvös. His example shows the strong Hungarian bonds to the German educational system, both pre-World War I and after. Subsequent generations of scientists and mathematicians can be connected with Eötvös' activities at Budapest University which largely defined a school of internationally recognized scientists who went to Germany before or after World War I and later left for the US after the rise of Nazism (Frank 2009).

My case study on Germany in the Weimar period in turn discusses to what extent new media, in this case radio, were able to complement established institutions of higher and further education like schools and universities with novel possibilities that would so to 
speak allow workers to attend school at night or that would extend the lecture hall of university professors to any rural home in the country. In putting German science radio into relation to the respective developments in other European countries and the US the article exhibits the special German case were popular science and science education can be found in a particular rich and seamlessly connected field that offered knowledge to all by means of mass media. This example finally also elucidates that the position of popular science between scientific education and science news is not a phenomenon of the scientific periphery but in particular in the course of the twentieth century a general phenomenon that may be of interest for any scholar of science education.

I would like to extend my warmest thanks to Michael R. Matthews, the editor of Science $\&$ Education, for the suggestion to transform a number of presentations and discussions of the symposium on "Communicating Science in twentieth century Europe-Comparative Perspectives" held at the XXIIIth International Congress of History of Science and Technology in Budapest in 2009 into a special issue and for his advice and assistance in many ways.

\section{References}

Daum, A. (2009). Varieties of popular science and the transformations of public knowledge: some historical reflections. Isis, 100, 319-332.

Frank, T. (2009). Double exile. Migrations of Jewish-Hungarian professionals through Germany to the United States, 1919-1945. Oxford: Oxford University Press.

Papanelopoulou, F., Nieto-Galan, A., \& Perdriguero, E. (Eds.). (2009). Popularizing science and technology in the European periphery, 1800-2000. Aldershot: Ashgate.

Secord, J. (2004). Knowledge in transit. Isis, 95, 654-672. 